\title{
Aging and Life Management System of Reactor Pressure Vessel $^{*}$
}

\author{
Ya-Jin Liu, Jiang Guo, Kai-Kai Gu \\ School of Power and Mechanical Engineering, Wuhan University, Wuhan, China \\ E-mail:guo.river@163.com \\ Received May 16, 2011; revised June 16, 2011; July 10, 2011
}

\begin{abstract}
Reactor pressure vessel (RPV), the only key component that can not be replaced in nuclear power plants (NPPs), is the main barrier against the radioactive leakage. The lifetime of NPPs is dependent heavily on the life of RPV, and thus, the aging and life research on a RPV is a key factor in determining the life extension of NPPs. The purpose of this paper is to introduce an aging and life management system for an operating RPV which can be used as a reference of the lifetime extension. In order to realize the objective, an aging and life management system was developed. It is an comprehensive knowledge management system that integrates decentralized information and serves as a valuable data center. Based on the storage and management of RPV state information and operation data, this system provides real-time monitoring of important operating parameters, evaluation of irradiation embrittlement, and RPV aging assessment. Therefore, it is anticipated that the developed system can be used as an efficient tool for aging and life estimation of RPV.
\end{abstract}

Keywords: Reactor Pressure Vessel, Nuclear Power Plants, Aging and Life Management

\section{Introduction}

As the main barrier against the radioactive leakage, reactor pressure vessel (RPV) is the unique component of nuclear power plants (NPPs). So, the lifetime of NPPs largely depends on the RPV. The aging and life research on a RPV is a key factor in determining the life extension of NPPs. Due to the important function of RPV in the safety of NPPs, it is essential to keep structure integral and function perfect under not only normal operating conditions but also the test conditions or accident conditions, and avoid the non-ductile fracture or radioactive leakage.

The implementation of RPV aging evaluation management needs information such as raw data of RPV designing, manufacturing, installment and debugging, real-time operation data, daily maintenance information and operation experience feedback. But all the information is scattered over many different departments. As a result, it is important for the RPV aging and life management to obtain, organize, share, update and innovate the discrete information with a scientific method, and

*Project supported by National Natural Science Foundation of China (51077102); Project supported by Scholarship Award for Excellent Doctoral Student granted by Ministry of Education. make it available. To solve this problem, the aging and life management system of RPV is presented, the function reference model of aging and life management is discussed, the general architecture is established, and the principle and methods of information organization are particularly introduced.

\section{Research Status}

In the development of RPV aging management system, the corresponding regulations, standard and guide are promulgated by IAEA, NRC and ASME/ASTM. These regulations, standard and guide provide the standards of property parameters of RPV material and the corrective measures when necessary, so as to ensure the structural integrity of RPV.

In the aging management research and implementation, much work has been done in United States, French and other nuclear countries. These works include the aging mechanism, structural integrity, online monitoring, inservice inspection and anti-ageing measures. Meanwhile, the economy analysis work for the life management also begins.

In database construction, based on the decades of operating experience, the major foreign nuclear countries 
possess relatively complete database. On the basis of the database, several aging management software systems are developed which make the aging management more objective and accurate.

Domestic researches on RPV aging management are still at their early stage. The researches and practices mainly focus on the nuclear plant. The achievements of the research in form, content and implementing effects are far from perfect. There is still a long way to go to form systematic industry rules and regulations. Meanwhile, the critical technology of inspection and monitoring still depends on foreign research institutions because of the lack of independent intellectual property rights. Thus, it is essential to improve our scientific research strength and develop the RPV aging management system with independent intellectual property rights.

Although many NPPs have their own aging Management databases, but the operating experience in recent years shows that, the lack of raw data, historical operating information, and historical maintenance data exerts a bad effect on the RPV aging management, especially on the trend analysis and prediction of the component performance and remaining life, and the judgment and evaluation of the degradation, failure and fault caused by aging effects. Moreover, there is no platform for the information exchange among domestic NPPs. The circumstances are not conducive to information sharing and the deepening development of the RPV aging management.

\section{Objectives and Functions}

\subsection{Objectives}

In order to improve aging and life management of the NPPs, we need to ensure the security, reliability and efficiency of the plants by searching for the problems brought by accelerated aging resulting from design defects, changes, rebuilding, and environment, building aging assessment and life prediction model and developing practical measures for improvement. And all these works should be based on the condition monitoring information and historical data.

In the early time of the NPPs, the incomplete collection of equipment information, the lack of raw data and technology and the relatively low evaluation level have no significant effects on the daily production. However, they will certainly exert bad effects on the evaluation of plant life, safety margin, and aging trend.

There are three main aims of this system. The first one is to collect various data, records and information needed by the aging and life management. The second one is to store the electronic data information by database. And the last one is to mine the key performance index from massive historical and real-time data and determine whether specific values within the normal range. It is hoped that the developed system can help users to complete the process of information perception, knowledge modeling and knowledge analysis, and train new technical personnel. The details are shown in the Table $\mathbf{1}$.

Nowadays because AI cannot yet completely replace human kind, this system can be used as an effective tool to help accelerating and shortening the thinking process. With the further understanding of RPV aging mechanism and the continuous development of the aging and life assessment level at home and abroad, the system information will be gradually improved, and the knowledge will be further enriched, thus it can lay a solid foundation for the researches of RPV aging and life management.

\subsection{Functions}

Based on the comprehensive study, actual demand, and the relevant studies for references, the functions of the system are shown in Figure 1.

There are six modules which are basic information management, in-service inspection management, water chemistry and operation management, maintenance management, experiences feedback, aging analysis and assessment.

1) Basic Information Management. This module is designed to manage the raw data of RPV in designing, manufacturing, installment and debugging in 3D model.

2) In-service Inspection Management. This module mainly provides in-service inspection, including defect management, defect analysis, trend analysis and inspection reports.

3) Water Chemistry and Operation Management. This module is used to manage water chemistry information, operation information, transient parameter statistics, and overhaul control and analysis.

4) Maintenance Management. This module is used to record the maintenance information of defective devices which includes maintenance tools, maintenance process records, work ticket statistics, and trend analysis.

5) Experience Feedback Management. This module provides the interface to manage experience feedback at home and abroad, and lay the foundation for the aging

Table 1. The Objective of the System

\begin{tabular}{cl}
\hline Stages & \multicolumn{1}{c}{ Objectives } \\
\hline information & to obtain useful information from data of mul- \\
perception & ti-source, then summarize and integrate it \\
knowledge & to mine the key performance index from data of \\
modeling & multi-source and multi-dimensional \\
knowledge & to evaluate the RPV aging condition, predict its \\
analysis & aging extent, and present the mitigation measures \\
knowledge & to improve the intelligibility of information by \\
representation & virtual reality technology \\
\hline
\end{tabular}




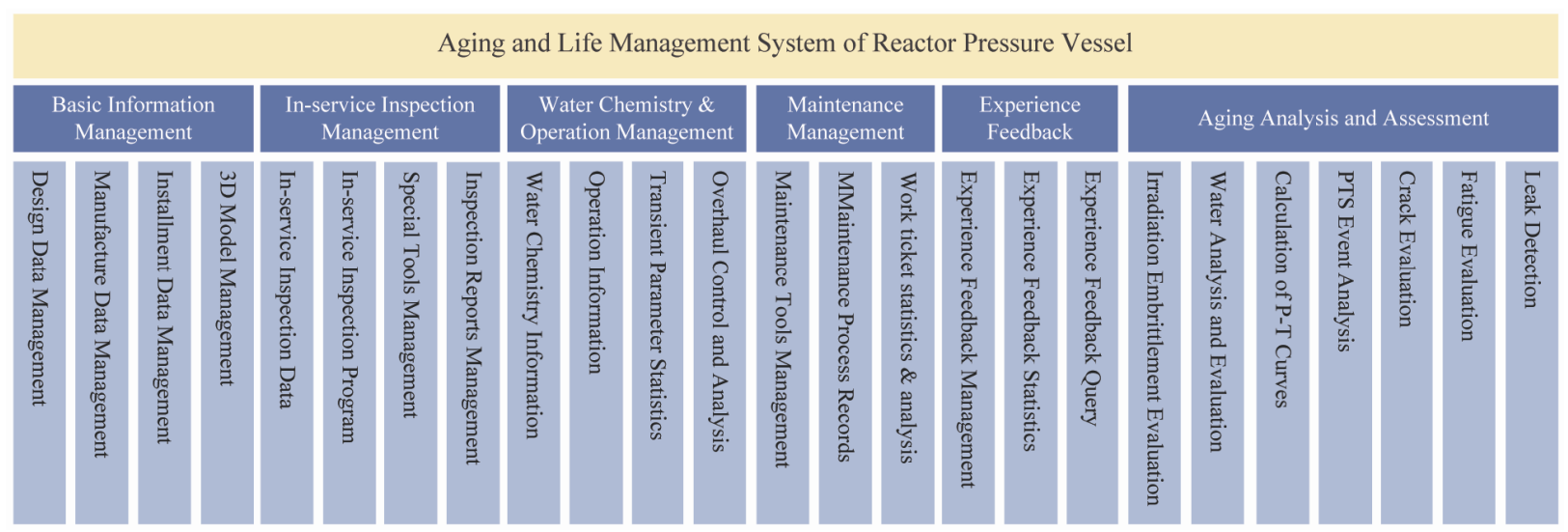

Figure 1. The Functions of RPV Aging and Life Management

evaluation follow-up.

6) Aging Analysis and Assessment. This is the core function of the system. The RPV aging condition is analyzed by employing different theories, such as irradiation embrittlement evaluation, water analysis and evaluation, calculation of P-T curves, PTS event analysis, crack evaluation, fatigue evaluation and leak detection

\section{Typical Applications}

\subsection{RPV 3D Model}

Because of its complex internal structure and high radioactivity, most of staff members fail to understand its structure in detail, especially its operation principle. In order to describe integral structure of RPV exactly, the 3D model is constructed by VR technology. Comparing with traditional 2D graphics, 3D model can describe the RPV structure in a more intuitive and visual method, so as to improve the intelligibility of information. The integral structure of RPV is shown in Figure 2.

Through this way, users can freely rotate and move the model to get appropriate direction and angle of observation as if they move it within the real environment. In

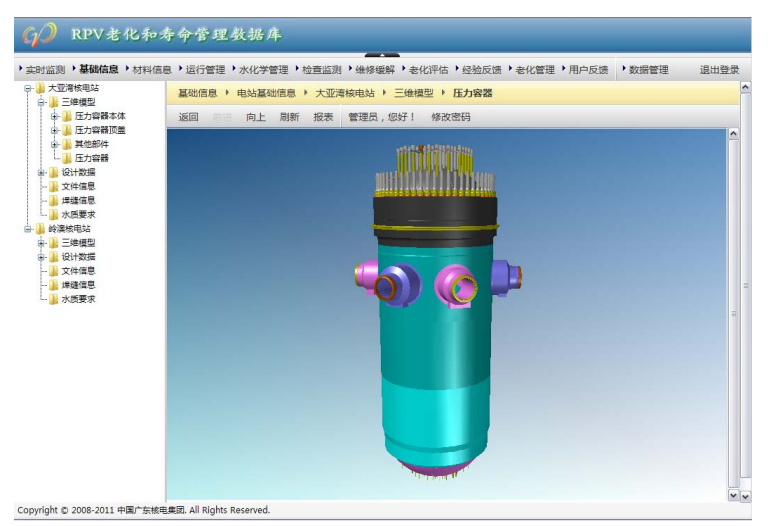

Figure 2. The Integral Model of RPV addition, users can choose the specified part of RPV for observation. The visualization of the top of RPV is presented in Figure 3.

\subsection{In-Service Inspection Management}

In-service inspection is of greatest importance for NPPs. In this module, a large amount of information about equipment performance is recorded, which is important for the aging evaluation of RPV.

There are several inspection methods, such as eddy current testing (ET), ultrasonic testing (UT), penetrant testing (PT), and radiographic testing (RT). When we use different inspection methods, we will record different contents accordingly. Thus, core work of this system is to find a reasonable method to organize this information. Based on the comprehensive investigation and analysis, this system adopts open system architecture and hierarchical designing method so as to organize and manage the contents of different inspection methods, thus making the management and display mode automatically consistent with the inspection methods.

Partial inspection results of bolts of the top of RPV are presented in Figure 4. The bolts are inspected through ET.

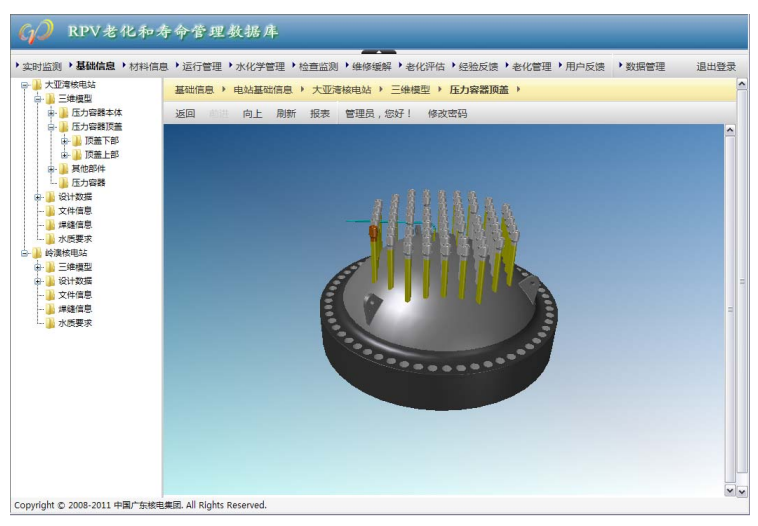

Figure 3. The Top Model of RPV 


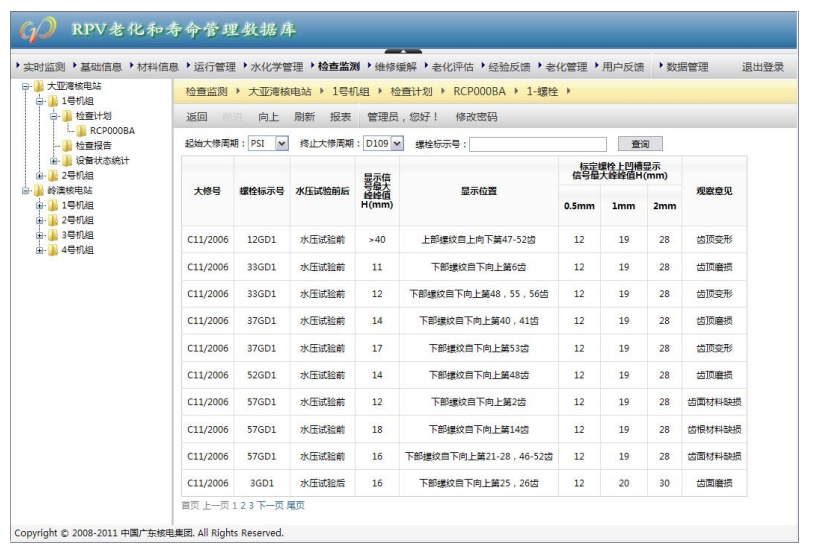

Figure 4. The Inspection Data of RPV

\subsection{Irradiation Embrittlement Evaluation}

Irradiation embrittlement evaluation of RPV is key to the aging analysis and assessment. Its accuracy and integrality directly determines the safety, reliability and economy of NPPs. The aging condtion can be evaluated on the basis of the in-service inspection information, historical operation data, maintenance information and experience feedback. Base metal and weld are the mainly objects of the irradiation embrittlement evaluation. The main assessment index includes USE, PTS, ART, etc.

Figure 5 shows the trend of USE of base metal and weld. The black line is for predictive value, the red line is for design value, and the green line is for value at the end of lifetime. Users can get the accurate value of USE when they move their mouse over the curves.

In addition, there are various sorts of information about irradiation embrittlement evaluation which are shown in Figure 6, such as irradiation monitoring data, basic information of material, install position of irradiation monitoring tube, and extraction scheme of irradiation monitoring tube. Comparative analysis of the information above can improve the veracity of evaluation results.

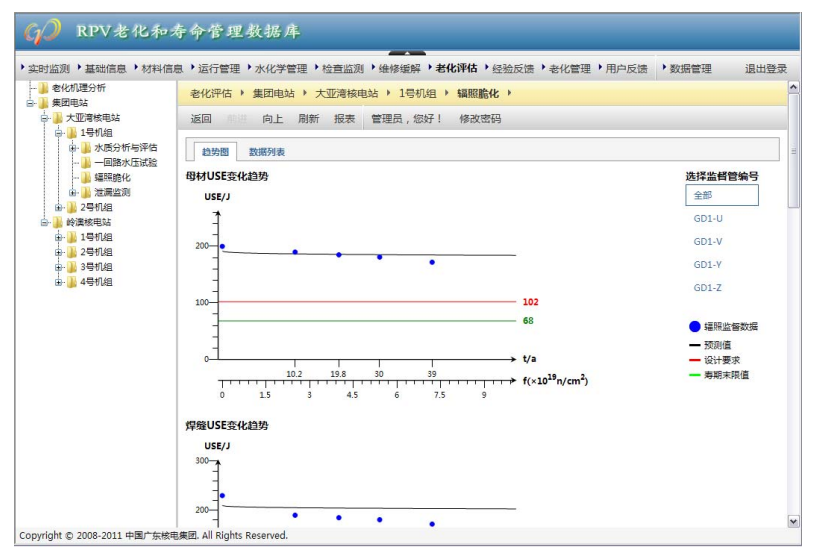

Figure 5. Irradiation Embrittlement Trend Analysis of RPV

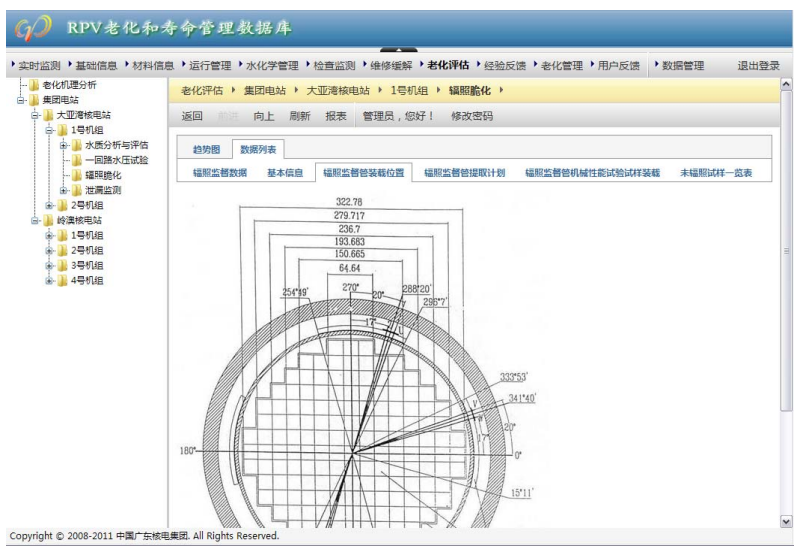

Figure 6. Irradiation Embrittlement Data Analysis of RPV

\section{Conclusions}

In this paper, a system aimed at aging and life evaluation of RPV is proposed. Based on the comprehensive investigation and analysis, the architecture of the system is designed and its functions are developed. This system has excellent capability, opening and expansibility.

1) It realizes the standardized management of aging information and the centralized management of the discrete data, which can be used in the evaluation afterwards.

2) The rational utilization of information is realized by using information technology, virtual reality technology and multi-agent technology, and it improves the utilization and understandability of information.

3) The special module for aging evaluation is developed. It evaluates the RPV aging condition from different aspects, and lays foundation for the integral evaluation.

This system is now in use in a NPP in China and proves to be an excellent system. It can effectively solve problems of aging management. However, the aging management in China is still at its initial stage, and much work needs to be done.

\section{References}

[1] D.-P. Kong, H. Li and H.-L. Zheng, "Life Management of Reactor Pressure Vessel at Qinshan Nuclear Power Plant," Nuclear Power Engineering, in Chinese, Vol. 29, No. 6, 2008, pp. 110-114.

[2] J. C. Kim, J. B. Choi, Y. S. Chang, Y. J. Kim and Y. W. Park, "Development of Web-Based Fatigue Life Evaluation System for Reactor Pressure Vessel," Safety and Structural Integrity, Vol. 120, No. 25, 2007, pp. 25-30.

[3] K. Anandakumaran, "Aging and Condition Monitoring Studies of Composite Insulation Cables Used in Nuclear Power Plants," Dielectrics and Electrical Insulation, IEEE Transactions on, Vol. 14, No. 1, 2007, pp. 227-237. doi:10.1109/TDEI.2007.302891 
[4] Z. F.Tong, H. Lin and G.-S. Ning, "Prediction Model on Irradiation Embrittlement of Low Copper Alloy Reactor Pressure Vessel Steels," Atomic Energy Science and Technology, in Chinese, Vol. 43, 2009, pp. 103-108.

[5] K. Onizawa and H. Matsuzawa, "Study on Factors Important to Structural Integrity of Reactor Pressure Vesselduring PTS with Regard to Fracture Probability," ASME Pressure Vessels and Piping Conference, Vol. 1, 2010, pp. 411-418.

[6] M. Brumovsky, "Ways for Extending the Reactor Pressure Vessel Lifetime," Proceedings of the ASME Pressure Vessels and Piping Conference, Vol. 7, 2009, pp. 129-135.

[7] G. Bezdikian, "Nuclear PWR Plants Life Management Reactor Pressure Vessel Strategic Evaluation for Fluence in Relation with Integrity Assessment," Proceedings of the ASME Pressure Vessels and Piping Conference, Vol. 7, 2009, pp. 579-587.

[8] W. F. Wu, C. S. Shin and C. H. Tsai, "A Reliability Assessment of Reactor Pressure Vessels," International Journal of Pressure Vessels and Piping, Vol. 57, No. 1, 1994, pp. 77-84. doi:10.1016/0308-0161(94)90100-7

[9] V. N. Shah and W. L. Server, “An aging Management Approach for Pressurized Water Reactor Pressure Vessels," International Journal of Pressure Vessels and Piping, Vol. 54, No. 1-2, 1993, pp. 317-340. doi:10.1016/0308-0161(93)90140-O

[10] M. A. Rinckel, "Reactor Pressure Vessel Integrity Program,” Nuclear Engineering and Design, Vol. 181, No. 1-3, 1998, pp. 17-39. doi:10.1016/S0029-5493(97)00332-4

[11] G. E. Lucas. "An Evolution of Understanding of Reactor Pressure Vessel Steel Embrittlement,” Journal of Nuclear Materials, Vol. 407, No. 1, 2010, pp. 59-69. doi:10.1016/j.jnucmat.2010.07.010

[12] S. Leclercq, D. Lidbury, S. V. Dyck, et al., "Perform 60-Prediction of the Effects of Radiation for Reactor Pressure Vessel and in-Core Materials Using Multi-Scale Modelling -60 Years Foreseen Plant Lifetime,” Journal of Nuclear Materials, Vol. 406, No. 1, 2010, pp. 193-203. doi:10.1016/j.jnucmat.2010.04.025

[13] J. M. Hyde, M. G. Burke, B. Gault, et al., "Atom Probe Tomography of Reactor Pressure Vessel Steels: An
Analysis of Data Integrity,” Ultramicroscopy, Vol. 111, No. 6, 2011, pp. 676-682.

doi:10.1016/j.ultramic.2010.12.033

[14] J. Y. Huang, J. J. Yeh, R. C. Kuo, et al., "Fatigue Crack Growth Behavior of Reactor Pressure Vessel Steels in Air and High-Temperature Water Environments," International Journal of Pressure Vessels and Piping, Vol. 85, No. 11, 2008, pp. 772-781. doi:10.1016/j.ijpvp.2008.08.003

[15] F. J. Blom, "Reactor Pressure Vessel Embrittlement of NPP Borssele: Design Lifetime and Lifetime Extension,” Nuclear Engineering and Design, Vol. 237, No. 20-21, 2007, pp. 2098-2104. doi:10.1016/j.nucengdes.2007.02.008

[16] U. B. Baek, K. S. Ryu, A. Kim, et al., “Aging Estimation of Reactor Pressure Vessel in the Field Using Magnetic Properties," Journal of Loss Prevention in the Process Industries, Vol. 22, No. 6, 2009, pp. 971-974. doi:10.1016/j.jlp.2009.06.014

[17] A. Al Mazouzi, A. Alamo, D. Lidbury, et al., "Perform 60: Prediction of the Effects of Radiation for Reactor Pressure Vessel and in-Core Materials Using Multi-Scale Modelling -60 Years Foreseen Plant Lifetime,” Nuclear Engineering and Design, in Press, Corrected Proof.

[18] G. Bezdikian, "Nuclear PWR Plants Life Management Reactor Pressure Vessel Strategic Evaluation for Fluence in Relation with Integrity Assessment," American Society of Mechanical Engineers, New York, 2009.

[19] P. Pareige, P. Auger and J. C. Van Duysen, "Effects of Neutron Radiation on the Aging of Nuclear Reactor Pressure Vessel Steel-Observation at the Atomic Level Using an Atomic Probe,” Journal De Physique Iv, Vol. 11, No. 1, 2001, pp. 39-48.

[20] D. P. G. Lidbury, A. H. Sherry, B. R. Bass, et al., "Validation of Constraint-Based Methodology in Structural Integrity of Ferritic Steels for Nuclear Reactor Pressure Vessels," Fatigue \& Fracture of Engineering Materials \& Structures, Vol. 29, No. 9-10, 2006, pp. 829-849. doi:10.1111/j.1460-2695.2006.01057.x

[21] C. A. English and J. M. Hyde, "Radiation Embrittlement of Reactor Pressure Vessel Steels,” In: I. Milne, R. O. Ritchie and B. Karihaloo, Comprehensive Structural Integrity, Pergamon, Oxford, 2003, pp. 351-398. 